\title{
AN XPS STUDY OF TARNISHING OF A GOLD MASK FROM A PRE-COLUMBIAN CULTURE
}

D.M. Bastidas ${ }^{a,}{ }^{*}$ E. Cano ${ }^{a}$, A.G. González ${ }^{b}$, S. Fajardo ${ }^{a}$, R. Lleras-Pérez ${ }^{c}$, E. Campo-Montero ${ }^{d}$, F.J. Belzunce-Varela ${ }^{e}$, J.M. Bastidas ${ }^{a}$

a CENIM-Centro Nacional de Investigaciones Metalúrgicas, CSIC, Avda. Gregorio del Amo 8, 28040 Madrid, Spain

${ }^{b}$ Departamento de Ciencia de los Materiales, Universidad de Antioquía, Medellín, Colombia

${ }^{c}$ Museo del Oro, Banco de la República, Bogotá, Colombia

d Departamento de Metalurgia y Ciencia de los Materiales, Universidad Pedagógica y Tecnológica de Colombia, Tunja, Colombia

e E.P.S. de Ingenieros de Gijón, Departamento de Ciencia de los Materiales, Campus Universitario, Universidad de Oviedo, 33203 Gijón (Asturias), Spain

* Corresponding author. Tel.: +34 91553 8900; fax: +34 915347425.

E-mail address: david.bastidas@cenim.csic.es (D.M. Bastidas).

\section{KEYWORDS:}

Calima-Nariguera mask; Hammered gold; Tarnishing; Corrosion

\section{ABSTRACT}

The tarnishing originated on a hammered gold mask was analysed. Red tarnishing was observed after three years of storage in an indoor environment in the Gold Museum of Banco de la República, Bogotá, Colombia. Silver sulphide $\left(\mathrm{Ag}_{2} \mathrm{~S}\right)$ and silver sulphate $\left(\mathrm{Ag}_{2} \mathrm{SO}_{4}\right)$ compounds were identified as the origin of the tarnishing phenomenon, which is attributed to environmental contamination. Atomic absorption spectroscopy (AAS) and X-ray photoelectron spectroscopy (XPS) techniques were used. 


\section{INTRODUCTION}

The Calima was a pre-Columbian culture that dominated southwest Colombia in the Yotoco period, between $100 \mathrm{BC}$ and $700 \mathrm{AD}$. The Calima produced many gold artefacts, usually symbolic objects representing the social hierarchies, interpretations of man and nature, and the perception of life and death. The Nariguera was a funerary mask that was used throughout the Yotoco period in the burials of important persons in the Calima culture. It was placed over the mouth of the deceased person. Its shape could represent a snake or a half-moon, or could transform the face of a man into the face of a feline. The Nariguera was typically adorned by a number of gold tabs hanging from the main part of the mask [1].

Colombian metallurgists were great innovators in pre-Hispanic America, cultivating styles such as lost-wax casting and hammering manufacturing techniques and achieving gilded finishes by oxidation [2]. It is known that gilded silver can suffer damage after a short time due to silver diffusion through the gold layer. In an environment with sulphur contamination, sulphuration processes can give rise to a blackish layer.

Gold alloys are subject to tarnishing when exposed to high humidity sulphur-containing atmospheres [3]. The formation of thin tarnish layers on decorative objects produces an aesthetically unacceptable brownish colouration $[4,5]$. As a noble metal, silver presents high corrosion resistance and is easily protected by a passive film in different environments. Silver also has a tendency to form complex ions in solution [6-8].

The aim of this paper is to analyse the origin of red coloured tarnish layers which appeared on the tabs hanging from a Nariguera mask stored for a three-year period in an apparently pollution-free environment in the Gold Museum of Banco de la República, Bogotá, Colombia.

\section{MATERIALS AND METHODS}

Fig. 1 shows the Nariguera mask and a detail of one of the ornamental tabs upon which some red coloured tarnishing was observed after three years of storage. The specimen (Fig. 1) is identified as: number 004520; culture Calima; function Nariguera; complex shape with hanging tabs; manufacturing technique hammering; dimensions $8.4 \mathrm{f} 10.5 \mathrm{~cm}$; weight $8.80 \mathrm{~g}$. It was discovered in archaeological excavations performed in the town of Restrepo in the Cauca valley, Colombia.

One of the mask's tabs was analysed using the atomic absorption spectroscopy (AAS) technique, yielding the following chemical composition: 75.7 wt.\% Au, 22.9 wt.\% Ag, and 1.4 wt.\% Cu.

X-ray photoelectron spectroscopy (XPS) experiments were conducted to determine the surface chemical composition using a VG Microtech Model MT 500 spectrophotometer with an Mg $\mathrm{Ka}_{1.2}$ anode $\mathrm{X}$-ray source $(\mathrm{hv}=1253.6 \mathrm{eV})$, with a primary beam energy of $15 \mathrm{kV}$ and an electron current of $20 \mathrm{~mA}$. The pressure in the analysis chamber was maintained at $1 \times 10^{-9} \mathrm{Torr}$ 
throughout the measurements. The regions of interest were $\mathrm{O} 1 \mathrm{~s}, \mathrm{C} 1 \mathrm{~s}, \mathrm{Au} 4 \mathrm{f}, \mathrm{Ag} 3 \mathrm{~d}, \mathrm{~s} 2 \mathrm{p}, \mathrm{Cu}$ $2 p$, Si $2 p, C l 2 p$, and $\mathrm{Na} 1 \mathrm{~s}$.

Table 1 shows the atmospheric conditions of the room and the showcase in the Gold Museum where the Nariguera is exhibited. The glass case is made of carbon steel covered with a hot curing organic paint and safety glass, and the stand is made of stainless steel.

\section{RESULTS}

Fig. 2 shows an XPS spectrum of the as-received specimen, with identification of the main peaks. Both silver and gold from the base alloy are identified, but copper is not observed (peak at $932.5 \mathrm{eV}$ ), indicating that it has been removed from the surface of the specimen. This surface enrichment of the more noble metals (gold and silver) may be attributed to selective dissolution of the copper, which was probably intentionally performed during manufacturing in order to improve the item's appearance.

The absence of copper in the spectrum in Fig. 2 indicates that the reddish tarnishing cannot be attributed to the formation of a cuprite layer $\left(\mathrm{Cu}_{2} \mathrm{O}\right)$, which has a dark red colour.

In addition to the base metals, chlorine, oxygen, sodium, carbon, sulphur and silicon are also detected (see Fig. 2). In order to obtain more detailed information on the chemical state of these elements, high-resolution XPS spectra have been obtained.

Fig. 3 shows a high-resolution XPS spectrum for $\mathrm{Ag} 3 \mathrm{~d}$. The spectrum can be fitted with a single thin $(1.2 \mathrm{eV} F W M H)$ doublet with a binding energy (BE) of $368.1 \mathrm{eV}$ for the $3 \mathrm{~d}_{5 / 2}$ peak and $374.1 \mathrm{eV}$ for the $3 \mathrm{~d}_{3 / 2}$. The $\mathrm{BE}$ of $\mathrm{Ag}, \mathrm{Ag}_{2} \mathrm{~S}, \mathrm{Ag}_{2} \mathrm{SO}_{4}$ and $\mathrm{AgCl}$ are very similar $(368.2,368.1,368.0$ and $368.3 \mathrm{eV}$, respectively), and therefore cannot be resolved. On the other hand, $\mathrm{Ag}_{2} \mathrm{O}$ and $\mathrm{AgO}$ lines fall at lower $\mathrm{BE}$, at $367.9 \mathrm{eV}$ and $367.5 \mathrm{eV}$, i.e. slightly lower than the main lines observed. However, at lower $\mathrm{BE}$, satellite peaks arising from the $\mathrm{K}_{\mathrm{a} 3}(359.6$ and $365.5 \mathrm{eV}$ ) and $\mathrm{K}_{\mathrm{a} 4}(363.7$ and $357.9 \mathrm{eV}$ ) emissions of the Mg X-ray anode can be observed in the spectrum. These peaks mask the possible presence of silver oxides, and therefore their presence or absence cannot be inferred from the Ag photoemission peak. Finally, the broad band at 353.1 $\mathrm{eV}$ can be attributed to the $A u 4 d_{3 / 2}$ region.

Fig. 4 shows a high-resolution XPS spectrum for S 2p. Three peaks can be observed. The peak located at $161.3 \mathrm{eV}$ can be attributed to sulphides, and the peak at $169.1 \mathrm{eV}$ can be attributed to sulphates. The peak at lower BE corresponds to the Si $2 p$ line. According to its energy (154.3 eV), this peak can be attributed to $\mathrm{SiO}_{2}$.

Fig. 5 shows a high-resolution XPS spectrum for Au 4f. A maximum can be observed at $84.0 \mathrm{eV}$, which corresponds to metallic Au. No other components appear in this region, and therefore gold is only present in the metallic state, not forming any compound with the pollutants on the surface [8].

Fig. 6 shows a high-resolution XPS spectrum for $\mathrm{Cl} 2 \mathrm{p}$. There is a small contribution of $\mathrm{Cl}$, with a peak located at $198.0 \mathrm{eV}$. This energy corresponds to chlorides, but it is not possible to know whether in the form of sodium chloride $(\mathrm{NaCl})$ or forming a silver chloride $(\mathrm{AgCl})$. $\mathrm{BE}$ reported 
in the literature for both $\mathrm{NaCl}$ (from $198.3 \mathrm{eV}$ to $198.5 \mathrm{eV}$ ) and $\mathrm{AgCl}$ (from $198.6 \mathrm{eV}$ to 200.2 $\mathrm{eV}$ ) are a little higher than the BE found in the present study. The presence of the $\mathrm{Na}_{\text {KLL }}$ Auger peak (Fig. 2) indicates that sodium is present on the surface, but it is not possible to quantify its amount, since the photoemission peak of Na located at about $1072.2 \mathrm{eV}$ is overlapped with the $\mathrm{Cl}_{\llcorner M M}$ Auger line. As has already been mentioned, silver peaks (Fig. 3) do not allow the amount of $\mathrm{AgCl}$ to be quantified.

Fig. 7 shows a high-resolution XPS spectrum for 0 1s. Three contributions can be observed. The main one, at $533.0 \mathrm{eV}$, can be attributed to adsorbed water and/or $\mathrm{SiO}_{2}$. The second, at 531.8 $\mathrm{eV}$, may be assigned to oxygen in the sulphates and/or hydroxides. Finally there is a small contribution at $529.8 \mathrm{eV}$ which indicates the presence of a minor amount of silver oxides.

Table 2 shows the element composition of the surface, obtained using the areas of each line and the sensitivity factors reported in the literature [9]. The main element on the surface is carbon. The high-resolution spectrum (not included) shows that it is mainly in the form of $\mathrm{C}-\mathrm{C}$ or $\mathrm{C}-\mathrm{H}$, and can be attributed to surface contamination of the specimen. The ratio between the atomic concentration of gold/silver on the surface (1.19) is lower than in the bulk (1.81, according to AAS results), indicating silver enrichment in the tarnish layer. The ratios between oxygen and sulphur in the sulphate peaks (4.14) are very close to the stoichiometry of sulphates, and therefore the peak at $531.8 \mathrm{eV}$ can be attributed exclusively to this compound [10]. This is not the case with the peak at $533 \mathrm{eV}$, which has a greater concentration than the peak corresponding to $\mathrm{SiO}_{2}$, indicating that it also includes the contribution of adsorbed water.

\section{DISCUSSION}

Pure gold is resistant to corrosion, but gold alloys are known to be susceptible to tarnishing. Their corrosion resistance decreases as the amount of alloying elements increases $[3,4,11]$. Several metal sulphides have been identified on tarnished gold alloys: acanthite $\left(\mathrm{Ag}_{2} \mathrm{~S}\right)$, uytenbogaardite $\left(\mathrm{Ag}_{3} \mathrm{AuS}_{2}\right)$, petrovskaite (AgAuS) and chalcocite $\left(\mathrm{Cu}_{2} \mathrm{~S}\right)$ [11]. In the present case, XPS results have shown that no copper is present on the surface, and that gold is only present in the metallic form. Therefore the tarnish layer is composed only of silver sulphides.

Hydrogen sulphide $\left(\mathrm{H}_{2} \mathrm{~S}\right)$, a reduced sulphur compound, is a key pollutant due to its great capacity to tarnish silver and copper in a short time, even at levels far below the human olfatory limit (1- $10 \mu \mathrm{g} / \mathrm{m} 3)$. Carboxylic sulphide (COS), another common reduced sulphur compound, is generated mainly in rural environments. The main source of $\mathrm{H}_{2} \mathrm{~S}$ and COS inside buildings is the presence of human beings. It has been reported that one person in a classroom releases about $100 \mu \mathrm{g}$ of $\mathrm{H}_{2} \mathrm{~S}$ per hour [12].

The reaction rates for silver are known to be similar for both $\mathrm{H}_{2} \mathrm{~S}$ and COS, and the mechanisms are similar or identical $[13,14]$. This indicates that at similar concentrations the total tarnishing rate will be the sum of the $\mathrm{H}_{2} \mathrm{~S}$ and COS rates. In a museum environment COS is available at approximately twice the $\mathrm{H}_{2} \mathrm{~S}$ concentration, and therefore COS should cause most of the tarnishing of museum objects [15]. Kim reported the tarnishing process of silver in environments containing $\mathrm{H}_{2} \mathrm{~S}$ and nitrogen dioxide (NO2), and concluded that nitrogen dioxide played an important role as an ionic conductor [16]. 
According to Ankersmith et al. [15], a layer of $250 \AA$ of silver sulphide produces a visible yellowing, and would be produced by a concentration of $3.9 \mu \mathrm{g} / \mathrm{m3}$ in a one-year period. Considering that visible tarnishing has appeared after about 10 months, and that the tarnishing of the gold specimens is more than simple yellowing, it may be estimated that the Nariguera has been exposed to a $\mathrm{H}_{2} \mathrm{~S}$ concentration of more than $5 \mu \mathrm{g} / \mathrm{m} 3$ (3.55 ppb), or an equivalent concentration of COS. This result agrees with Table 1.

This concentration is higher than the average concentration of these pollutants in typical urban environments [15], and thus it is clear that there is an important sulphur source within the museum environment (see Table 1). It is a common notion that wool and other keratincontaining proteins (like hair and feathers) are an important source of sulphides, probably due to deterioration of cysteine-containing proteins [17]. However, some authors report that wool does not cause silver tarnishing except when exposed to high temperatures (not likely in a museum) or bright lighting. Wool carpets have been reported to tarnish silver when brightly illuminated [11]. In most cases, human emissions are likely to be the main source of sulphide compounds. It has been calculated that 10 visitors in a medium-sized gallery $\left(1000 \mathrm{~m}^{3}\right)$ would add approximately $0.1 \mathrm{ppb}$ of $\mathrm{H}_{2} \mathrm{~S}$ to the environment in 5 min [15].

In contrast to its reactivity with reduced sulphur compounds, the sulphidation of silver by sulphur dioxide $\left(\mathrm{SO}_{2}\right)$ is very slow, both in dry conditions and in the presence of water vapour. Unlike some other metals, silver do not naturally form a surface oxide [13]. Exposure to reduced sulphur compounds can produce a silver sulphide $\left(\mathrm{Ag}_{2} \mathrm{~S}\right)$ film. Long exposure times produce small amounts of a second component, which may be either silver oxide $\left(\mathrm{Ag}_{2} \mathrm{O}\right)$ or silver sulphate $\left(\mathrm{Ag}_{2} \mathrm{SO} 4\right)[14]$.

It is difficult to identify the origin of the $\mathrm{SiS}_{2}$ compound indicated in Fig. 4. It is probably due to residues of the prior cleaning of the specimens. Finally, the origin of chloride may be attributed to fingerprints deposited during handling of the specimen. The city of Bogotá and the town of Restrepo are both a long way from the sea, and so the contribution of marine aerosols may be considered negligible.

\section{CONCLUSIONS}

According to XPS results, the tarnish layer is composed of a mixture of silver sulphates and sulphides, with a minor contribution of silver oxides. Chlorides are also present on the surface but XPS analysis does not allow us to assess whether they are forming silver compounds or are only surface contamination by sodium chloride. Finally, the specimen also presents surface contamination by $\mathrm{SiO} 2$, hydrocarbons and adsorbed water.

The fast tarnishing rate indicates that the Nariguera has been exposed to a high sulphide concentration $\left(\mathrm{H}_{2} \mathrm{~S}\right.$ and/or $\left.\mathrm{COS}\right)$, in excess of $5 \mu \mathrm{g} / \mathrm{m}^{3}$. The origin of these sulphides is unknown, but is probably related with human emissions. 


\section{ACKNOWLEDGEMENT}

D.M. Bastidas expresses his gratitude to the CSIC of Spain for his contract under the I3P Program co-financed by the European Social Fund.

\section{REFERENCES}

[1] C. Plazas, Int. J. South Am. Archaeol. 1 (2007) 33.

[2] C. Degrigny, M. Wéry, V. Vescoli, J.M. Blengino, Stud. Conserv. 41 (1996) 170.

[3] C. Courty, H.J. Mathieu, D. Landolt, Werkst. Korros. 42 (1991) 288.

[4] E. Angelini, E. Cordano, S. Kaciulis, G. Mattogno, L. Pandolfi, M.R. Pinasco, F. Rosalbino, Surf. Interface Anal. 30 (2000) 50.

[5] V.K. Kaushik, J. Electron Spectrosc. Relat. Phenom. 56 (1991) 273.

[6] G.W. Walkiden, R.A. Jarman, Corrosion, in: L.L. Shreir R.A. Jarman G.T. Burstein (Eds.), Butterworth Heinemann, London, 1994, pp. 6-9.

[7] M. García-Heras, M.A. Villegas, E. Cano, F. Cortés-Pizarro, J.M. Bastidas, J. Cult. Herit. 5 (2004) 311.

[8] E. Cano, J. Simancas, J.M. Bastidas, Plat. Surf. Finish. 88 (2001) 80.

[9] C.D. Wagner, J. Vac. Sci. Technol. 15 (1978) 518.

[10] J.F. Moulder, W.F. Stickle, P.E. Sobol, K.D. Bombem, in: J. Chastain (Ed.), Handbook of Xray Photoelectron Spectroscopy, Perkin-Elmer, Eden Prairie, Minnesota, 1992.

[11] L. Selwyn, in: L. Selwyn (Ed.), Metals and Corrosion: A Handbook for the Conservation Professional, The Canadian Conservation Institute, Ottawa, Canada, 2004, p. 78.

[12] J. Tétreault, in: J. Tétreault (Ed.), Airborne Pollutants in Museums, Galleries, and Archives: Risk Assessment, Control Strategies and Preservation Management, The Canadian Conservation Institute, Ottawa, Canada, 2003, pp. 10-11.

[13] J.P. Franey, G.W. Kammlott, T.E. Graedel, Corros. Sci. 25 (1985) 133.

[14] T.E. Graedel, J.P. Franey, G.J. Gualtieri, G.W. Kammlott, D.L. Malm, Corros. Sci. 25 (1985) 1163.

[15] H.A. Ankersmith, N.H. Tennent, S.F. Watts, Atmos. Environ. 39 (2005) 695.

[16] H. Kim, Mater. Corros. 54 (2003) 243.

[17] P.B. Hatchfield, in: P.B. Hatchfield (Ed.), Pollutants in the Museum Environment, Archetype Publications Ltd., London, UK, 2002, p. 10. 


\section{FIGURE CAPTIONS}

Fig. 1. (a) Calima-Nariguera mask, (b) tarnished specimen tested.

Fig. 2. XPS general spectrum of the tarnished specimen.

Fig. 3. XPS high-resolution spectrum for $\mathrm{Ag} 3 \mathrm{~d}$.

Fig. 4. XPS high-resolution spectrum for $S 2 p$.

Fig. 5. XPS high-resolution spectrum for $A u 4 f$.

Fig. 6. XPS high-resolution spectrum for $\mathrm{Cl} 2 \mathrm{p}$.

Fig. 7. XPS high-resolution spectrum for $01 \mathrm{~s}$. 
Table 1. Average environmental conditions of the Gold Museum, Banco de la República, Bogotá, Colombia.

\begin{tabular}{lll}
\hline Environmental Conditions & Showcase & Room \\
\hline Temperature, o $\mathrm{C}$ & 24.97 & 23.80 \\
Relative Humidity $(\mathrm{RH}), \%$ & 41.07 & 43.2 \\
Volatile Organic Compounds (VOC), ppm & 0.11 & 0.12 \\
Carbon Monoxide $(\mathrm{CO}), \mathrm{ppm}$ & 2.90 & 3.60 \\
Nitrogen Dioxide $\left(\mathrm{NO}_{2}\right), \mathrm{ppm}$ & 0.08 & 0.03 \\
Sulphur Dioxide $\left(\mathrm{SO}_{2}\right), \mathrm{ppm}$ & 0.005 & 0.01 \\
Hydrogen Sulphide $\left(\mathrm{H}_{2} \mathrm{~S}\right), \mathrm{ppm}$ & 0.01 & 0.02 \\
Lighting, lx & 240 Horizontal Surface & 404 Horizontal Surface \\
& 99 Vertical Surface & 177 Vertical Surface \\
Particles in Suspension, mg/m & 0.14 & 0.17 \\
\hline
\end{tabular}


Table 2. Atomic concentration of the elements identified by XPS, obtained from the areas of the photoemission lines and the corresponding sensitivity factors.

\begin{tabular}{|c|c|c|c|c|c|c|c|c|c|c|}
\hline \multirow[b]{2}{*}{ Element } & \multirow[b]{2}{*}{$\mathrm{Au}$} & \multirow[b]{2}{*}{$\mathrm{Ag}$} & \multirow[b]{2}{*}{$\mathrm{Cl}$} & \multicolumn{2}{|l|}{$S$} & \multirow[b]{2}{*}{$\mathrm{Si}$} & \multirow[b]{2}{*}{ C } & \multicolumn{3}{|l|}{0} \\
\hline & & & & $\mathrm{S}^{2-}$ & $\left(\mathrm{SO}_{4}\right)^{2-}$ & & & $\mathrm{SiO}_{2} / \mathrm{H}_{2} \mathrm{O}$ & $\left(\mathrm{SO}_{4}\right)^{2-}$ & $\mathrm{O}^{2-}$ \\
\hline Atomic \% & 4.4 & 3.7 & 1.3 & 3.4 & 3.6 & 4.0 & 48.1 & 16.6 & 14.2 & 0.7 \\
\hline
\end{tabular}

